\title{
An Extension to Late Rentierism, using a Comparative Compound Diversification Index, to Show the Movement Towards Mixed Mode Economic Diversification and Development, in the GCC States
}

\author{
John W Lang ${ }^{1} \&$ N. Aldori ${ }^{2}$ \\ ${ }^{1}$ Sheffield University Management School, University of Sheffield \\ ${ }^{2}$ School of Government and International Affairs, Durham University \\ Correspondence: Dr. John W Lang, Sheffield University Management School, University of Sheffield, Sheffield, S10 \\ 1FL, UK.
}

Received: January 9, 2020

doi:10.11114/bms.v6i1.4752
Accepted: March 1, $2020 \quad$ Online Published: March 3, 2020

URL: https://doi.org/10.11114/bms.v6i1.4752

\begin{abstract}
This study draws together several strands of research, including late rentierism, economic diversification in the GCC states of the UAE, Qatar, Kuwait, Oman, Kingdom of Saudi Arabia, and Bahrain, in an attempt to measure the direction of the trend towards a mixed mode economy. A comparative compound diversification index (CCDI) is developed to measure the movement along the late rentier continuum of development. The research is based on data from various Global Innovation Index (GII) reports and databases, which provide the attributes used to measure the overall trends. It creates a foundation for the ongoing measurement of this trend over the coming decade, and provides a correlation with the oil price fluctuations, thereby measuring how much the GCC states dependence may be changing, however incrementally, and however marginally that may be. The study does confirm a move towards a mixed mode economy, with knowledge-based, technology and innovation led activities at the heart of that incremental and marginal change.
\end{abstract}

Keywords: late rentierism, CCDI, GII, GCC States, GCC economic diversification, sovereign wealth funds

\section{Introduction}

The main objective and focus of this paper, is to develop an index that will show the comparative trends of the extent of diversification, of the GCC economies, into a mixed mode, more diversified economic activities, with specific reference to more knowledge-based, technologically advanced, innovation driven activities. The index, which we call the Comparative Compound Diversification Index (CCDI) is constructed from attributes, categorised into a simple, Political/Legal, Economic, Social, Technological, Environmental factors (PESTEL) heuristic. The research is rooted in the late rentierist paradigm, with the CCDI acting as a measure of the degree of travel along the continuum into late rentierism.

The CCDI will show the absolute and comparative differences between the Gulf countries, despite similar resource endowments (Kinninmont 2015, p 11), in terms of their diversification, into technology, knowledge-based, innovation applications, ecosystems. The succeeding sections review late rentierism; the part played by ecosystems and clusters of innovation in the diversification process; the role of the sovereign wealth funds in diversification; the creation of the CCDI and analyses of the results.

\section{Rentierism and Late Rentierism}

The rentier resource abundance and dependence of the GCC states, on oil and gas, led to lack of: strategic consideration in the diversification of their economic activities; investment in intellectual and social capital; innovation and R\&D in knowledge-based assets; industrial production, exposing the states to highly variable market conditions in global oil and gas commodity exchanges. The upshot is that the issue of dependency means that economic diversification, into productive activities rather than pure allocative activity, has not always been at the top of the GCC countries' wider socio-political agenda.

The recent variability in the price of a barrel of crude oil has brought attendant risks to the economy, the investment activities of the state and its rentier state incomes (Al-Maamary et. al. 2016). Allocative states, such as the GCC 
countries, “....are characterized by the state being largely dislocated from the national economy. Because of the large income from, for example, exports of oil, gas or other 'rent earning commodities', the state is not forced to tax the local economy to finance its activities." The state therefore views "its role as that of distributing the revenues which flow into the country. As such, allocation and production states must be understood as opposite extremes on a continuum." (Luciani 2015b, p 71) The finite nature of the rentier resource, and the volatility in its market value, due to price and rent accrual fluctuations, has helped to focus the attention of the GCC states on the need for alternate revenue streams, more aligned with a diversified, "production oriented" economy.

Moore (2004), Gray (2011) and Moritz (2016) all make the point that the GCC countries are not the same as they were when rentier state theory (RST) became the dominant paradigm, and equally now, in 2019, the GCC states have evolved (more diversified their economic activities) further, giving rise to viewing the development through a revisionist lens of late rentierism.

"Late rentierism creates a particular type of state that is more responsive, globalised and strategic in its thinking" (Gray 2011, p 24). The "active economic and development policies"; permeable country boundaries, opening up to globalisation; "an undemocratic but responsive state", "entrepreneurial state capitalism"; the state as strategic thinker; "innovative foreign policies" are all characteristics of late rentierism (Gray 2011).

International Financial Institutions (IFIs) including the World Bank, the IMF, the World Economic Forum, have all produced a myriad of reports indicating that the GCC countries will need to strategically develop and diversify their economies in order to sustain growth with the background volatility of oil revenues and prices (see data in appendix 6). These institutions, and academic authors including Hvidt (2011), Gray (2011), Levins (2012), Hertog (2015), Ozyavuz and Schmid (2015), Ulrichsen (2017) all point to late, and post rentierism as being characterised by the growth of what may be termed as a diversified knowledge and technology focused degree of economic activities. Oil rents may underwrite the development process into mixed mode, oil centric but knowledge based economic diversification, but the authors mentioned above, all believe that there is incremental, if marginal change. Gray (2011, p 2) recognises, in his concept of late rentierism, that the GCC states "[are] seemingly spending their rentier wealth more intelligently to develop their economies and societies, diversify away from their strong reliance on oil, build new international images and roles for their cities and states, and even change the state's relationship with society. Yet at the same time, the tenets of RST seem to retain a general validity."

The GCC countries have begun to put a premium on alternative development options away from hydrocarbon dependence, whilst maintaining monarchic forms of governance and a balance, or even tension, in the social contract with their citizens. Oil revenues and exports have been the mainstay of the GCC countries' economies, and their development has been invariably hydrocarbon centric in nature. Ennis (2014, p 127) is critical of the depth and degree of the movement away from the hegemony of hydrocarbon as the source of economic dependency, towards a new entrepreneurial dawn, however she does accede that: an important direction of public policy related to economic growth and innovation "involves instruments promoting entrepreneurship." A mixed mode features an environment where "people, culture, and technology" [network] "to catalyse creativity, trigger invention, and accelerate innovation across scientific and technological disciplines, public and private sectors . . . in a top-town, policy-driven as well as bottom-up, entrepreneurship-empowered fashion. (Ennis 2014, p 127).

Price volatility, especially in the five-year period of this study, from $2014-2018$, has concentrated the minds and focussed the countries' leaders' thoughts in seeking alternative investments, diversifying into unrelated markets and industries. The economic development through diversification is a feature of late rentierism, and has been a stated ambition of the GCC countries' various vision documents, over the past decade (Miniaoui and Schiliro, 2016; Hvidt, 2013). However, according to Hvidt (2013, p1), "the past record of diversification has yielded only meagre results."

Due to the crude oil price volatility over the past decade, post the global financial crisis of 2008, and since the 2016 low of \$26.21 (Macrotrends, 2019), all of the countries in the GCC have had major refocussing of their vision plans, promoting long-term growth strategies, including the "Vision 2020 in Oman, Vision 2021 in the United Arab Emirates, Vision 2030 in Bahrain, and Qatar National Vision 2030 and the most recent new Vision 2030 in Saudi Arabia" (Miniaoui and Schiliro 2016, p4; Arab Development Portal, 2017). The earlier vision plans were criticized for not having specific measurable action frameworks; there was too often a "me too" style to the documents, even though each GCC state has its own identity; and, at the time of their creation, crude prices were higher and more stable. This has meant revisions were necessary to account for the negative aspects associated with oil price and rent accrual volatility.

All of the GCC vision plans take long term views of the necessity to develop strategies "towards more diversification of the economy and to reduce the continued reliance on oil (the share of oil in GDP)." (Mahmah and Kandil, 2019, p 77). Despite the intent towards a diversified economy, figure 1 shows the core dependence on oil revenues, of all of the GCC states. However, this in and of itself is not problematic, as long as fiscal prudence is maintained, and the necessary 
developmental ecosystems are created, with a congruence between the Political/legal; economic; social; technological; environmental factors underpinning that development. As Mahmah and Kandil (2019, p 88) highlight "the pace of fiscal consolidation should be pursued gradually over time to strike the necessary balance between short-term financing needs and long-term non-energy growth objectives." If the GCC states maintain what we believe is a strategic intent on their part, maintaining a trend of fiscal support going forward, the non-hydrocarbon economic sector growth is possible, if at a slow but purposively managed pace. The question to what extent the trend, has been positive, using the technologically, knowledge-based innovation investments (as actual and wider proxy diversification) has been positive, we hope to show this using the CCDI.

The imperative to diversify economies has been reinforced by several authors, including Cherif et. al. (2017, p36) of the IMF, whose research "confirm that diversified economies do better than mono-sector economies over the long run." The global marketplace has become more and more technologically, knowledge based and innovation driven (TKI), and this has not been lost on the GCC countries' diversification policies. This TKI economic diversification route is implemented at varying rates and with varying degrees of strategic intent, by each GCC country, as will be seen from the empirical data presented later in this paper.

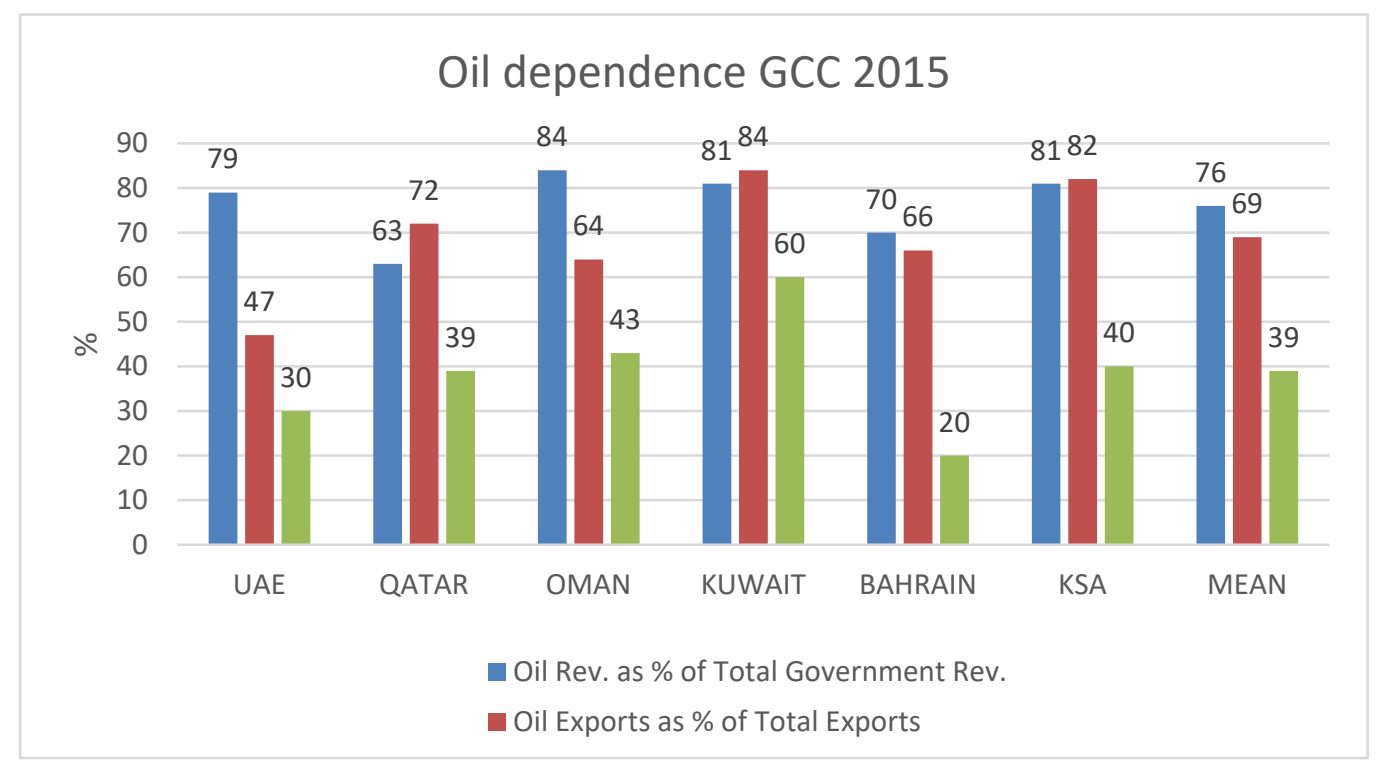

Figure 1. Oil Dependence in the GCC, 2015 (Mahmah and Kandil, 2019, p79)

This purposive strategic intent towards "diversification", is in part to change the risk reward profile of the economy; of investments; to reduce the dependence, in the long run, on hydrocarbon rents; to create and promote more diversified areas of economic growth, and requires a foresight that is underpinned by investment vehicles such the sovereign wealth funds, in order to begin to create a mixed mode economy. We use the term mixed mode to mean a deliberate movement towards investments and rents that begin to recalibrate the economic activity towards high growth, future investments. Additionally, in using the term deliberate movement towards the mixed mode economy, we wish to reframe the perspective from the resource dependency / resource curse viewpoint, to an acceptance that there is a centripetal economic force, based on hydrocarbon resource rentierism, and hydrocarbon abundance, to measure the comparative diversification trends, over the five-year period (2014 - 2018), specifically into technology, knowledge based, innovation (TKI) led business areas. The "[c]urrent development plans [mentioned above], point unanimously to diversification as the means to secure the stability and the sustainability of income levels in the future." (Hvidt, 2013, p1). As Yamada (2019) points out, from behavioural economics, the choices made by the ruling elites' reluctance to make radical economic changes, may be caught somewhat in a catch 22 , due to the constraints imposed by the boundedly rational decision making, based on incomplete information of the potential results (returns) of their future diversification plans. In this sense they are caught between behavioural resistance to change and requirement to change.

The ability of the GCC states to achieve their stated diversification ambitions requires what Hvidt (2013, p 1) has called the "reinvigoration of the private sector". This implies that the formal business environment needs quality standards, rules and practices, in place in order to engender trust and facilitate business and trading processes. This is part of the remit of the political / legal $(\mathrm{P} / \mathrm{L})$ state framework in creating the necessary and sufficient conditions in which markets may develop and diversification of the economy may occur. Therefore, this is one of a number of important attributes in our 
theoretical framework, outlined in the subsequent section. They may also be subjected "to a range of human tendencies, such as the "endowment effect" (overvaluation of the item already in one's hand) and the "ambiguity effect" (aversion to the risks when the probability of the alternative choice is unknown)." (Yamada, 2019, pp 14-15). This is a factor in the moderate and gradual nature of change towards the mixed mode economy, as our empirical evidence will show.

Technology, knowledge- based businesses, information and communications technology (ICT) feature in all of the development plans of the Gulf States, and as pointed out by Tok (2018, p8), in order to stimulate economic growth, "state governments must develop broader strategies while coordinating policies in the areas of scientific research, technology commercialization, ICT investments, education....intellectual property (IP)" all within a political / legislative environment that is conducive to business innovation and development. The implication being that there is a congruent mutuality in all of the political/legal; social; economic; technological; environmental transformations, requiring a managed, progressive, recalibration of the states' dispositions towards mixed mode economic diversification. Because of the dominance of the state, and state-owned enterprises (SOEs), in the economies, they have a major role to play in the creation of incubatory ecosystems that provide the relevant technological, knowledge-based, innovation led mixed mode diversification programmes, using hydrocarbon rents effectively. The implication is that entrepreneurial and innovation led ecosystems need a coordinated and congruent political/legal; economic and social policy; technological; and environmental approach to diversification.

\section{Ecosystems, Clusters and Keystone Firms}

Ecosystems, and local TKI clusters, in industrial districts, may be fostered from within and between international universities, through alliances and collaborative links with international businesses. In turn, clusters have grown around specific geographical points (cities and districts) and core keystone firms, which are more often than not SOEs, in telecommunications; satellite technology; aerospace; healthcare and hospitality sectors, which attract funding, nurture innovation linkages, cross border alliances, co-located intellectual and social capital exchanges, generating and diffusing knowledge. (Miniaoui and Schilirò, 2017). According to Gulfbusiness.com (March 2019), examples include the KSAs public / private partnerships and incubation programmes such as the Badir Programme for Technology Incubators and Accelerators, helping to create an innovation hub, projected to be on target for creating 600 tech. start-ups, employing 3600 people by 2020. The UAE government set up the first "advancement research centre" in Dubai. Named the Dubai Affiliate centre, the focus of its R\&D efforts is in areas such as artificial intelligence, blockchain and cryptocurrency, and precision medicine. The main affiliate is based in San Francisco, not by coincidence, a proximate location to Silicon Valley, in the US. Not to be outdone by the larger economies of the UAE and KSA, Bahrain, has created the Fintech Bay hub, with investors that include, Microsoft, Cisco, and Batelco. The Oxford Business Group in (The Report: Bahrain 2019, p 1) extolls the virtues of new FinTech legislation in Bahrain, along with investments "in the financial technology niche played a key role in encouraging support and investment in the country's financial services industry."

Generically, FinTech ecosystems grow from central hubs of innovation clusters (clusters being geographically localised, whilst ecosystems are more geographically dispersed, but both often grow around keystone firms) as they promote efficiency in markets and systems crucial to attracting relevant innovation oriented intellectual capital to stimulate the diversified economies. As Diemers et. al. (2015) point out, "FinTech ecosystems enable growth opportunities for many sectors, including software, data analytics, payments, platforms (e.g., peer-to-peer lending and trading), mobile banking, and algorithmic asset management systems." Furthermore, they state that "[g]overnments must implement and enforce policies and a regulatory environment that will ease the development of the FinTech ecosystem. Doing so encourages entrepreneurial activity and hiring by financial services and technology firms. It also improves the country's overall competitiveness." (Diemers et. al. 2015, pp 4 -5). In these incubatory environments, entrepreneurs benefit from transferrable skills and expertise, in which to nurture their innovations.

\subsection{The Role of Sovereign Wealth Funds}

The GCC countries' sovereign wealth funds (SWF) have an increasing part to play in many of the diversification initiatives, and may be used as asset bases from which to initiate and invest in wider ecosystems developments. The SWFs have been used a vehicle for GCC states to create new sources of revenue, through their diversified business ecosystem investments (higher risk/return typically in technology innovations), which also extend their influence (economically and politically), and create returns (economic) that help reduce dependency on oil (Krane, 2018, Ulrichsen 2017). The SWFs may be viewed as a reserve of assets, which help provide a conduit to mixed mode diversified economic activities of the Gulf States. This supports the proposition made earlier, that the GCC states are developing towards new economic strategic intents.

There have been some significant investments by GCC SWFs in technology and intellectual capital and property-based firms and business activities. For example: Magic Leap, a US start-up, received an investment from the Saudi Arabian 
Public Investment Fund (PIF) of \$400m, along with investments from Google and Alibaba. This would put Magic Leap at the heart of some of the largest business / market ecosystems in technology and innovation in the world, along with even larger investment stakes in Softbank's vision fund $(\$ 45 \mathrm{bn})$, and $\$ 3.5 \mathrm{bn}$ in Uber. The Financial Times reported (March $7^{\text {th }}, 2018$ ), that "Saudi Arabia's crown prince Mohammed Bin Salman has been using the PIF as a vehicle to make bold investments that are intended to help diversify the country's economy from a reliance on oil". Softbank also received a $\$ 15 \mathrm{bn}$ investment in their Internet of Things Vison Fund from Abu Dhabi's Mubadala fund (Businessinsider.com).

The SWFs investment activities indicate a commitment to new state strategic imperatives, and experimentation in markets with higher risk profiles and potentially greater returns. Karen Young (2019, p 45) has pointed out that “...[the] high tech-focused investments, invites a certain level of risk. A willingness to borrow signals a sovereign wealth fund is more of an active investment fund, or a hedge fund, rather than a safe deposit of shared wealth." According to Young (2018, p 10), the state - societal relations are changing more dramatically since late 2014 in which "one opportunity is very clear: the transformations taking place in Gulf political economies now is unprecedented in terms of their revision of the state's concentration on the expansion of the private sector."

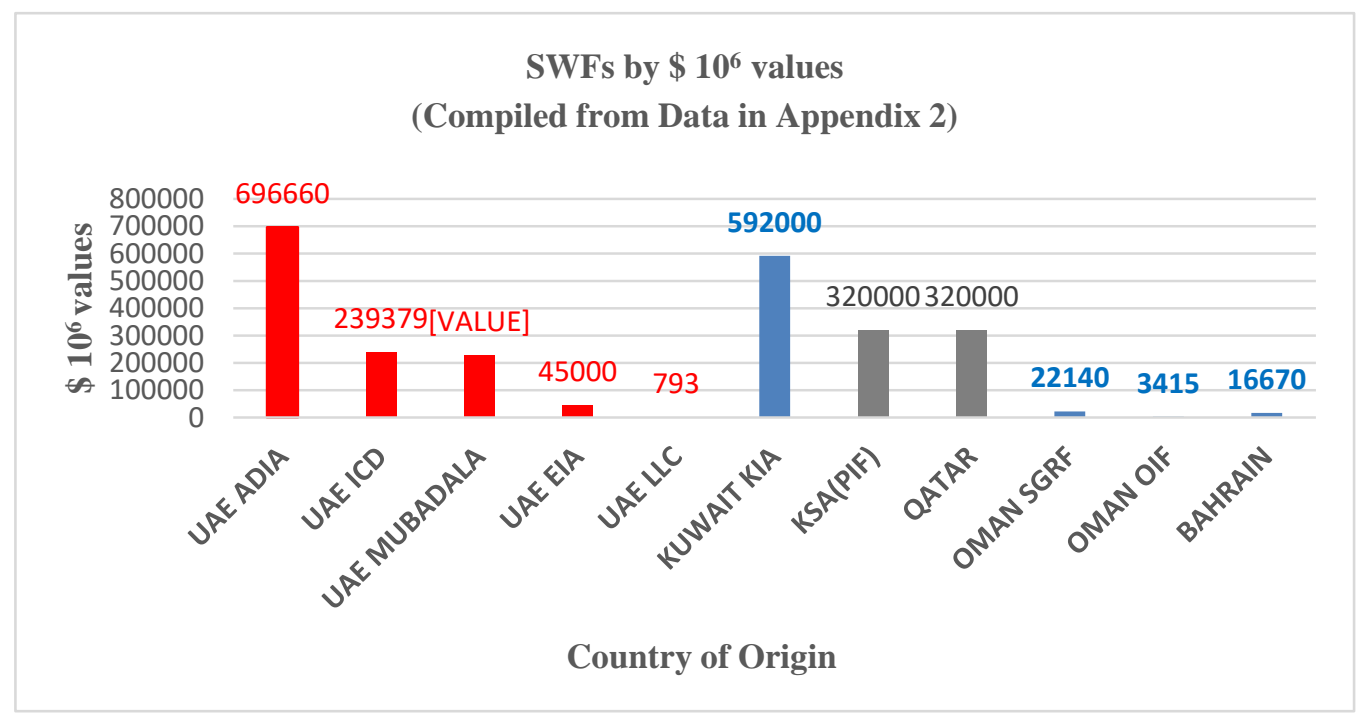

Figure 2. Sovereign Wealth Funds by size and country

(compiled from the data table in appendix $2 \& 2 \mathrm{a}$ )

All of the above discussions appear to indicate that there is a movement towards a more diversified economy, and that stimulation of technology, knowledge-based entrepreneurial activity appears to be the way that has been adopted, in high growth sectors. There is also a need for congruency between the political/legal, social, economic, technological and environmental (PESTEL) factor conditions as enablers of progress towards the mixed mode economies, as stated in the vison documents of the GCC states. With this in mind, we have created an index which will show the trend, from 2014 - 2018, and measure the comparative development, of the GCC countries, on the continuum of late rentierism, specifically related to technological, knowledge-based, ICT inputs and outputs (see appendix 1 for the list of attributes which are the compound variables that enabled us to create the index, the Comparative Compound Diversification Index, to measure the trend and comparative development of the GCC states).

\section{PESTEL Conceptual Framework \& Compound Attributes}

The attributes, making up the CCDI, were taken from the Global Innovation Index's (GII 2014 - 2018) database, published by INSEAD Business School, Cornell University and WIPO; and the World Intellectual Property Organisation. 56 attributes were purposively chosen for the CCDI creation, according to the centrality of importance to technology, knowledge-based, ICT sectors. These were then assigned to the PESTEL factors to calculate the mean values and the weighting loads for the CCDI calculations. Because of the way the way in which the CCDI has been structured it also allows the disaggregation into its constituent factors (the PL $-\mathrm{E}-\mathrm{S}-\mathrm{T}-\mathrm{E}$ ) for analytical purposes, creating sub-indexes which may then be re-aggregated to show the meta - data, as the CCDI. Table 1 shows the loading of the numbers of attributes, and their weights, assigned to each PESTEL factor. 
Table 1. The PESTEL Factors and their Attribute numbers and weight

\begin{tabular}{|lll|}
\hline CCDI & CCDI (PESTEL ATTRIBUTES) & \\
\hline PESTEL FACTORS & NO. & WEIGHT \\
\hline POLITICAL / LEGAL & $\mathbf{1 6}$ & $\mathbf{0 . 2 8}$ \\
\hline ECONOMIC & $\mathbf{7}$ & $\mathbf{0 . 1 3}$ \\
\hline SOCIAL & $\mathbf{8}$ & $\mathbf{0 . 1 4}$ \\
\hline TECHNOLOGICAL & $\mathbf{2 1}$ & $\mathbf{0 . 3 8}$ \\
\hline ENVIRONMENTAL & $\mathbf{4}$ & $\mathbf{0 . 0 7}$ \\
\hline TOTAL & & $\mathbf{1}$ \\
\hline
\end{tabular}

The choice of the attributes is listed in appendix 1. The CCDI shows the comparative trends in GCC inter and intra country diversification trends, according ultimately to the mean weights of the 56 attribute values, aggregated into the PESTEL heuristic, finally yielding the meta data index of the CCDI for each country.

$$
\mathrm{CCDI}=\sum_{2014}^{2018} \mu \mathrm{W}(\mathrm{P} / \mathrm{L}, \mathrm{E}, \mathrm{S}, \mathrm{T}, \mathrm{E})(\mathrm{UAE}, \mathrm{Q}, \mathrm{O}, \mathrm{K}, \mathrm{B}, \mathrm{KSA})
$$

The application, analysis and interpretation of the CCDI, its PESTEL factors and their attribute data will now be discussed, with respect to the GCC states of the United Arab Emirates (UAE); Qatar (Q); Oman (O); Kuwait (K); Bahrain (B) and the Kingdom of Saudi Arabia (KSA).

\section{Application, Analysis and Interpretation of CCDI Values}

The main proposition of this work is that the GCC states should be moving towards a mixed mode economic sector, however incrementally, with technology, knowledge-based, innovation at its heart. This would then reinforce the proposition that there is a move towards a mixed mode diversification of the economies, showing their strategic intent. Figure 3 shows the scores/values of the CCDI calculated over the five-year period, $2014-2018$, from the consolidated data on the attributes in appendix 1 and 1a. (The actual spreadsheet data sets are available on request from the authors).

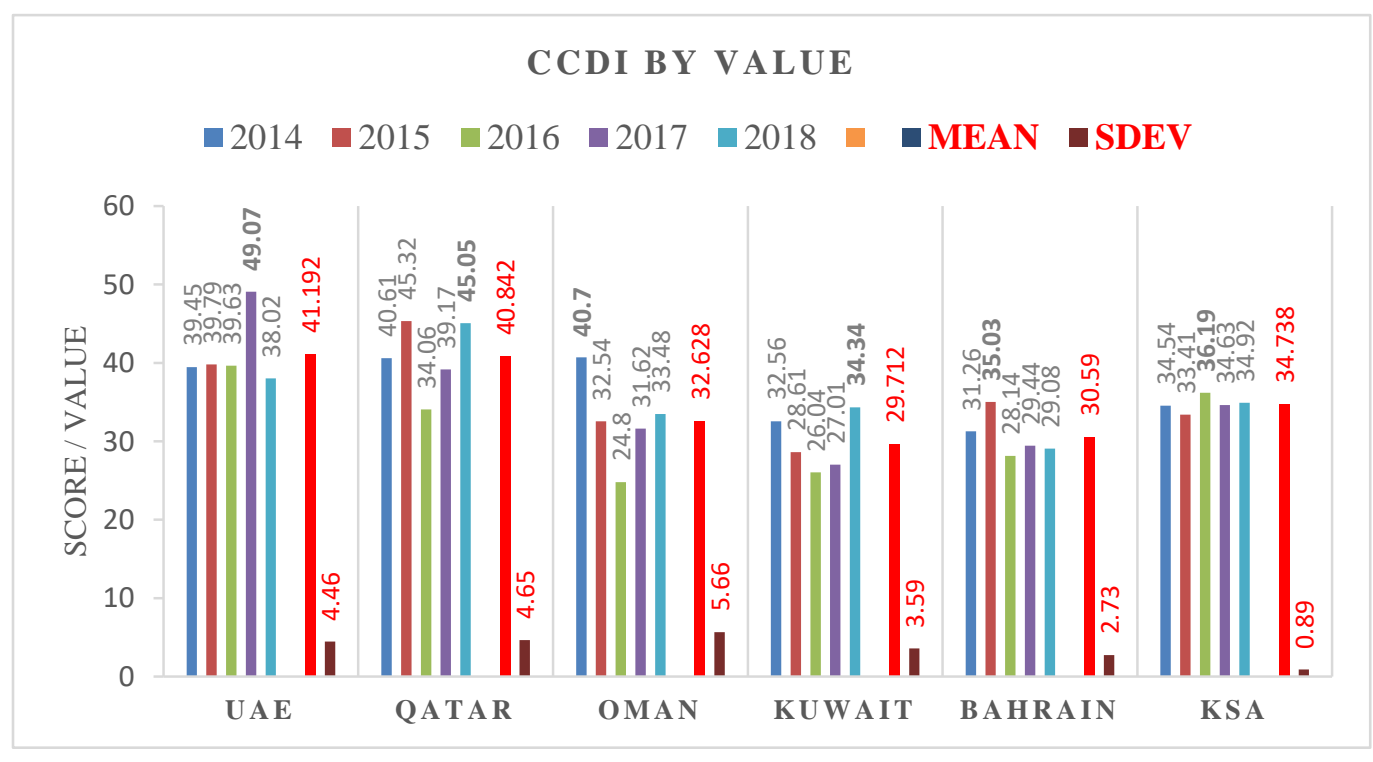

Figure 3. CCDI values of the GCC states

(Compiled and created by the authors based on original data from the GII reports 2014 - 2018)

The figure above shows the compound values for the CCDI (compounded from the PESTEL factors). The higher the 
value the further the country has developed, along the mixed mode diversification path. The UAE and Qatar clearly stand out with their average CCDI vales year on year since 2014 being 41.19 , and 40.84 respectively, with the average for all GCC countries at 35.4. The UAE shows a peaked value in 2017 reaching 49.07 CCDI and Qatar peaking in 2015 and 2018 at 45.32 and 45.05 CCDI respectively. The UAE measure is the highest in the overall trend average with all countries showing different year variations as to their investment pushes and consolidation years in the various innovation input attributes shown in appendix 1 . The country which has been consistent and stable with a very small standard deviation around it's mean score of 34.74 CCDI, is the Kingdom of Saudi Arabia. If we view the CCDI as a proxy measure for broader (PESTEL) successful, congruent reforms, which underpin the potential for diversification, in which the attributes in appendix 1 play a role, then the UAE and Qatar are clearly cognizant of the required investments, towards positive diversification, with the KSA also cognizant but more cautious in terms of the potential negative effect of instability (measured by the standard deviations, SDev) reflected in its very small SDev of the CCDI values from 2014 - 2018. If we take the SDev (CCDI 2014 -2018) as a proxy measure of risk, then the UAE, Qatar and Oman have been particularly willing to take investment risks in technology, knowledge- based, ICT innovation (shown in the attributes in appendix 1) developments in order to embark on the path of mixed mode economic diversification.

Figure 3 also shows that the GCC countries split into two groups with consistently higher value CCDI scores with respect to the PESTEL attribute values. The higher CCDI value group, includes the UAE $(\bar{x}=41.19)$, Qatar $(\bar{x}=40.84)$ and the KSA $(\bar{x}=34.74)$, which have CCDI values above or very near the mean CCDI values, taken over all countries for all years, of $\bar{x}=34.95$ (denoted by the dotted red line in figure 3 ). This figure also highlights a stable, incremental and/or consistently positive trend in diversification.

Being reminded that the CCDI shows a movement towards investment and creation of a fledgling innovation based economic sector, it would be expected that the higher scores on the CCDI would show a corresponding lower hydrocarbon revenue scores (and vice versa) in figure 4. This is indeed the case, with the UAE having the lowest average $43.68 \%$ gross revenues attributed to hydrocarbons, and Kuwait the highest average at $86.92 \%$. The anomaly is Qatar which has a CCDI value of 40.84 , whilst also maintaining a heavy average percentage revenue of $80.74 \%$. This is primarily due to the major macro infrastructural building programmes, roads, airports, airline, higher education institutions, world cup preparations, have all been fuelled by the rentier incomes from gas and oil.

It can be seen, in figure 4, that the rate of transition to a mixed mode economy, is different for each state, with Kuwait notably remaining highly dependent on the oil export rent revenues, and Qatar on gas revenues. However, the overall percentages for the GCC countries shows a marginal declining dependence, year on year, on hydrocarbon revenues (figure 4), and a corresponding marginal increase in the CCDI values year on year (figure 3 ).

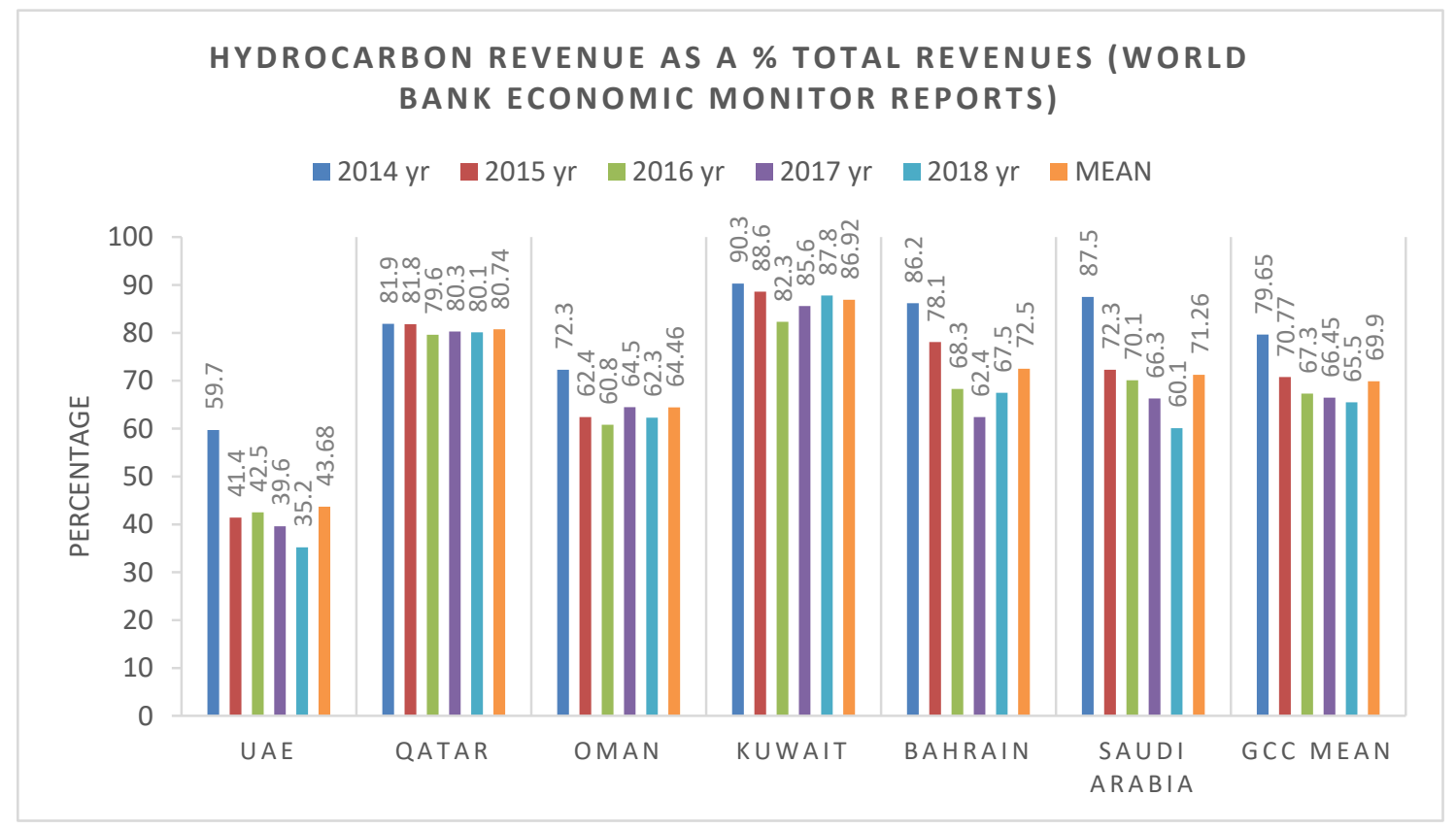

Figure 4. Revenues from Hydrocarbon as a \% of total revenues

(Data collated from: World Bank Economic Monitor Reports 2017 \& 18) 
The side by side year on year (yoy) changes in values of the CCDI, and the corresponding yoy change in the average price of crude oil in the same period, is shown in figure 5. This correspondence, that is, the direction of change of each state's change in the CCDI, shows which states have "managed" their diversification programmes well, even in the face of volatile oil price fluctuations. The UAE, and to a slightly lesser degree, KSA have maintained its CCDI diversification almost exactly in line with the oil price changes. Qatar and Kuwait have managed higher positive average increases in their mixed mode economic activity (measured by the CCDI), with Oman and Bahrain's diversification activities curtailed due to the average oil price change of $0.48 \%$ from 2014 - 2018. Qatar is less dependent on oil revenues than it is on gas which also mitigates the effect of oil price fluctuations.

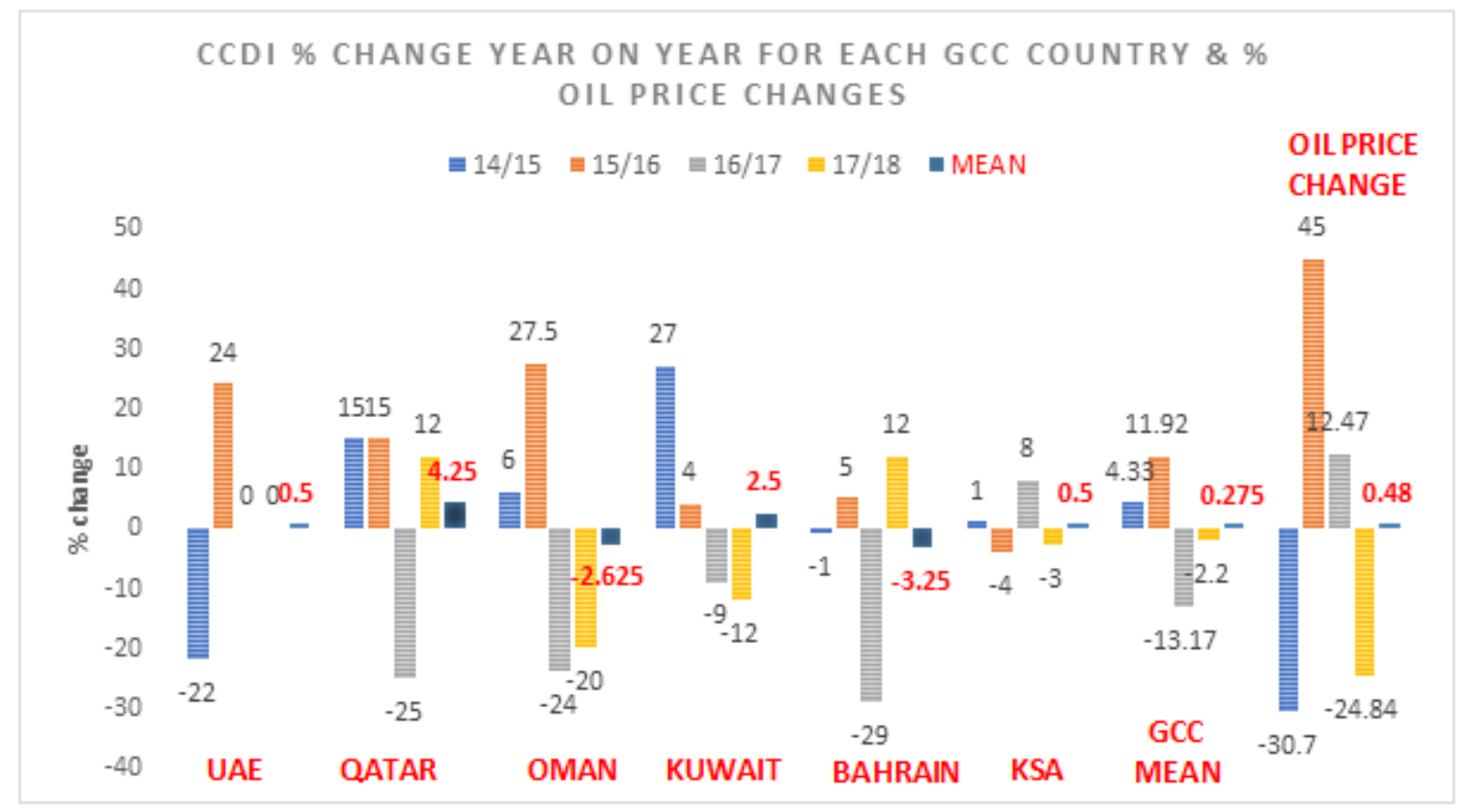

Figure 5. CCDI \% change year on year correlated with Oil price changes

(Compiled and created from attribute data in appendix 1, and from macrotrends.net)

The figure shows that Qatar has averaged a positive $4.25 \%$ growth in the CCDI year on year for the past five years. What is striking is that the CCDI measures shows a stuttering volatility in the path to innovation development, not the smooth trend that may be expected from states with visionary strategic development plans. Why would four of the five countries have shown dramatic negative change from 2016 to 2017? The answer appears to lie in the fact that the price of crude oil in February 2016 dropped to its lowest for over a decade, since the 2008 global financial crisis, recording a price of \$26.21. This seems to indicate that the default position became to euphemistically protect the supply side of oil, in order to raise the prices, which by years end had recovered to $\$ 52.33$.

It is conjectured here that when the price of oil is low, two of the GCC countries dramatically restrain their diversification and innovation development plans (measured by the CCDI), they are Bahrain and Oman. Two countries have made investments in their technology, knowledge-based, innovations (TKI), above the average of the crude prices, Qatar and Kuwait, with KSA and UAE maintaining a high degree of control, with average changes in their CCDI values in parity with crude price changes. The UAE and the KSA, in particular, show a remarkable degree of control and management of investments in the TKI sectors whilst displaying an awareness of potential fiscal problems that may occur if control is not exercised. However, in fairness all of the GCC states have, on average operated their diversification strategies steadily but with controlled conservatism. Figure 6 shows the remarkable consistency in rankings of the countries (measured by the CCDI and the SWFs) and reinforces the binary split in terms of diversification advancement. 


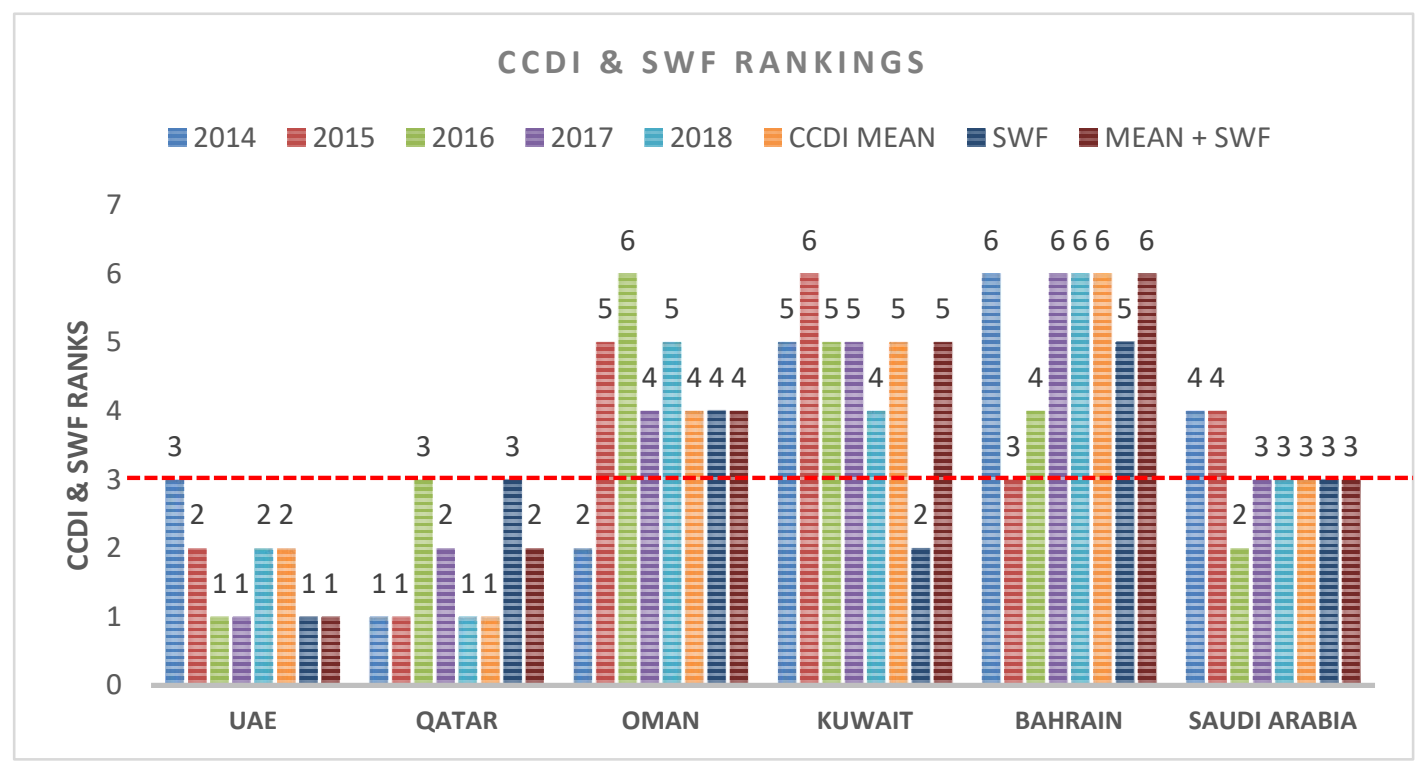

Figure 6. CCDI rankings of the GCC states

(Compiled and created from attribute data in appendix 1)

The UAE and Qatar rank consistently much higher than all other GCC neighbours. Qatar has a CCDI mean rank of 1, with the UAE second and the KSA $3^{\text {rd }}$, again reinforcing the "divide" between the GCC states, into three higher ranked countries, in terms of their measured CCDI diversification values. When we factor the SWFs into the ranking, the UAE ranks much higher than the rest, with Qatar coming second and the KSA remaining third in the rankings. The inclusion of the SWF within the overall CCDI was considered, but it's distortion effect in favour the UAE would be considerable, and so it is presented in figure 6 as complementary to our Index. This brings up one exception to the $3+3$ country split that is Kuwait, which has the second largest SWF.

Focusing on the business environment and the political and legislative facilitation of creating businesses, doing business and the quality of the legislative processes, the UAE holds primary position, as measured in the Political / Legal sub index in figure 7.

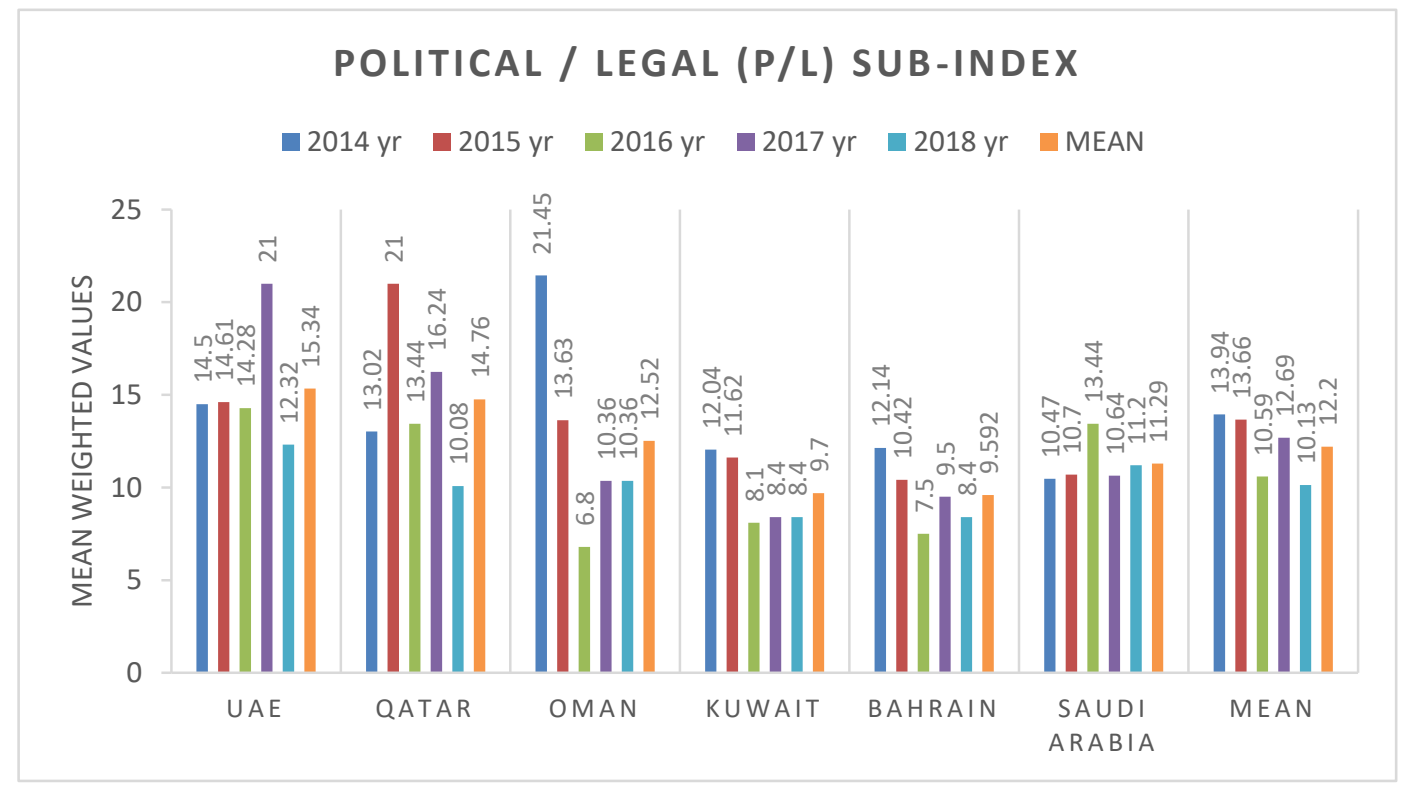

Figure 7. Political / Legal Sub Index values of the GCC states

(Compiled and created by the authors based on original data from the GII reports 2014 - 2018) 
Again, this may be triangulated with the "ease of doing business" report data (see World Bank, Doing Business, 2014 2018), in which the UAE is the country where business creation and growth has been most developed, in terms of its rankings relative to the other GCC states, followed closely by Qatar. The Pollical / Legal sub-index, which represents $28 \%$ of the CCDI, shows that over the past five years, the UAE, however only marginally outperforming Qatar on average, has been the most stable for business investment and potential growth, by having the most stable business environment; political stability and safety for investors (risk management); the highest expenditure per capita on research and development and scientific researchers; and the effectiveness of the government as arbiter of disputes and the implementation of a highly regarded reliable, in decision making terms (regulatory quality), of a regulatory framework. Both the UAE averaging 15.34 and Qatar at 14.76 over the past five years are substantially above the mean CCDI values of the attributes related to business environment conduciveness and quality of the politico-legal framework. This is carried through to the overall CCDI ranks of the two states. The technology sub-index (figure 8), which has the largest weighting of attributes, making up 38\% of the CCDI, mirrors the pattern shown in the political-legal sub index, meaning that information

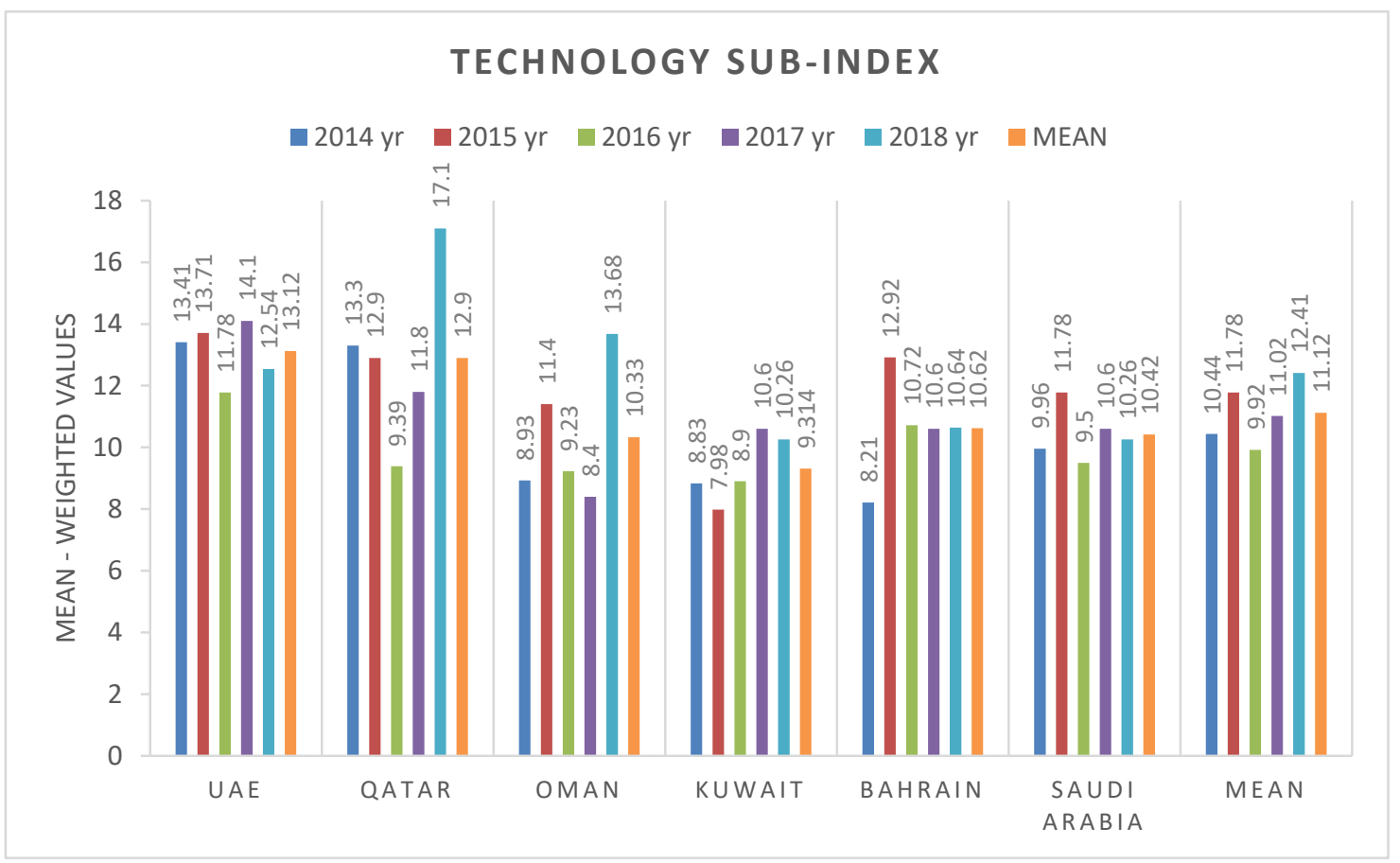

Figure 8. Technological sub-index

(Compiled and created by the author based on original data from the GII reports 2014 - 2018)

and communications infrastructure is well developed, particularly in the UAE and Qatar, both above the average for the GCC as a group, and substantially above the lowest average performer, Kuwait. Again, in the case of Kuwait, this reflects the strong percentage of revenues, maintained by Kuwait, on hydrocarbons of $86.92 \%$. The diffusion of knowledge through local incubatory business ecosystems is strong in Qatar, as is the impact on the society and economy knowledge creation and its impact, in the forms of patents and innovations. Kuwait's diversification programmes are mainly related to or revolve around downstream application in the oil sector, reinforcing hydrocarbon as a centre of gravity for technical educational programmes. However, recent plans in "Bahrain, Oman, Qatar, KSA and the UAE demonstrate that there is a strong will to support entrepreneurship and innovation with the aim of diversifying the economy" (Miniaoui and Schiliro 2016, p 20). The creation of a business environment conducive to start-ups and developing ecosystems, is important for diversification to succeed, and so it could be predicted to see a strong correlation between the technology factors and political/legal factors in the sub-indexes. This is precisely the case, with a Pearson " $r$ " value of 0.916 , and indicating a strong correlation between technological diversification and the business environment nurturing it. This is the strongest correlation between all sub-indexes.

The economic sub-index (figure 9) is instrumental in measuring investment, trade and competition in the business environment, which is indicative of the funding needed by the private sector to create the ecosystem networks of technology and knowledge-based innovations. 


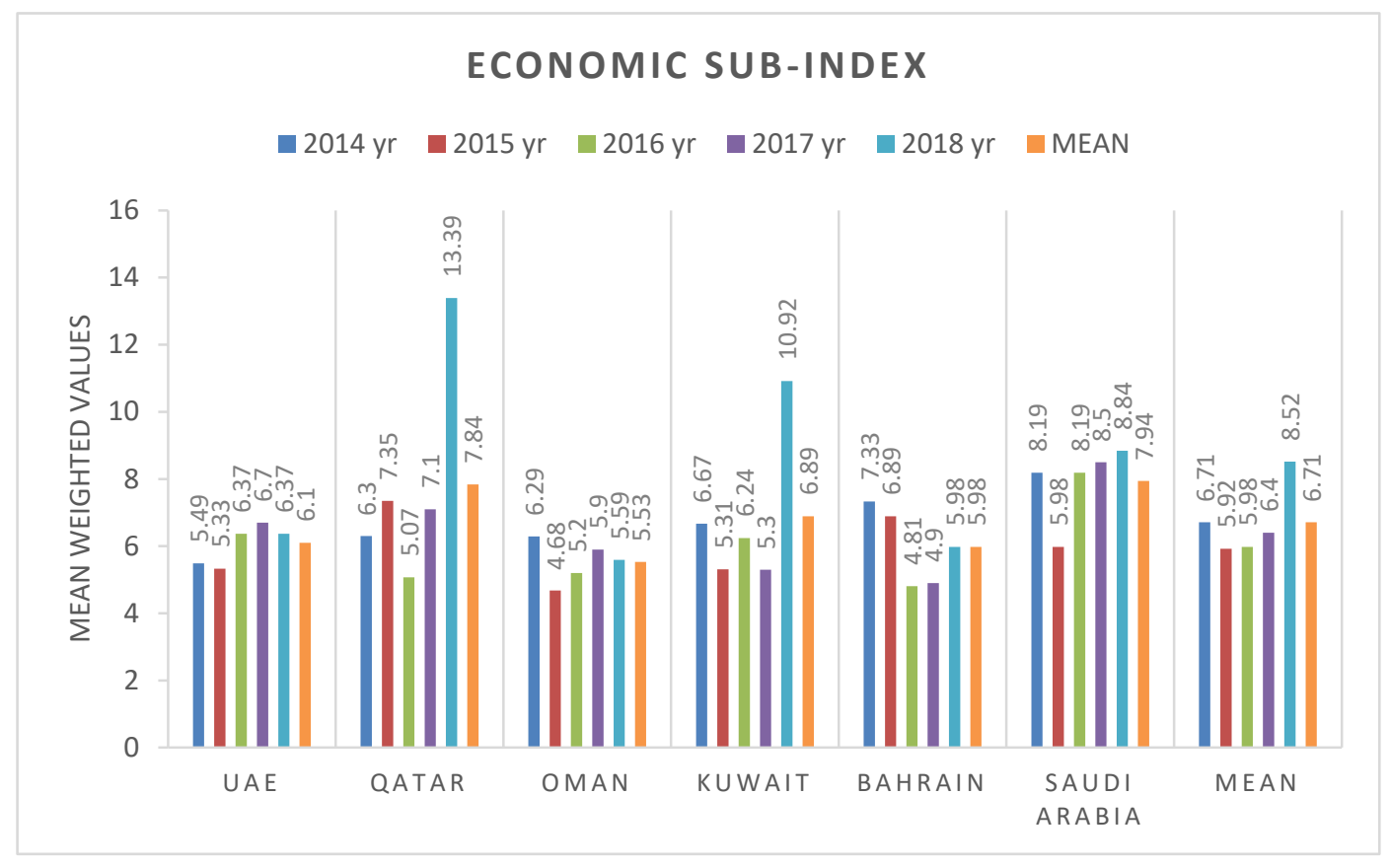

Figure 9. Economic sub-index

(Compiled and created by the author based on original data from the GII reports 2014 - 2018)

A feature of the economy sub-index (figure 9) is the relative stability of the UAE over the 2014/18 period, and its operating level marginally below the average of the GCC group. By contrast, Qatar and Kuwait clearly made substantial advances in the growth of trade and investment in 2018 which raised their five-year averages above the averaged benchmark figure for all countries. If the outlier figures are removed for 2018 from both countries, then Qatar registers an average sub-economic index score of 6.45 and Kuwait a score of 5.85. These would appear to be more in line with the rest of the GCC, and so a note of caution is taken for this element of the sub-index.

By contrast to the above, the social sub-index shows the UAE and KSA possessing reasonable stability in their investments in knowledge intensive employment, and the growth of their global expenditure on R\&D (GERD), which is a feature of the sovereign wealth funds investing in wider regional and global knowledge intensive, innovation led ecosystems. The main feature of the social sub-index is that it is made up of knowledge intensive education, investment and training in global R\&D science and technology.

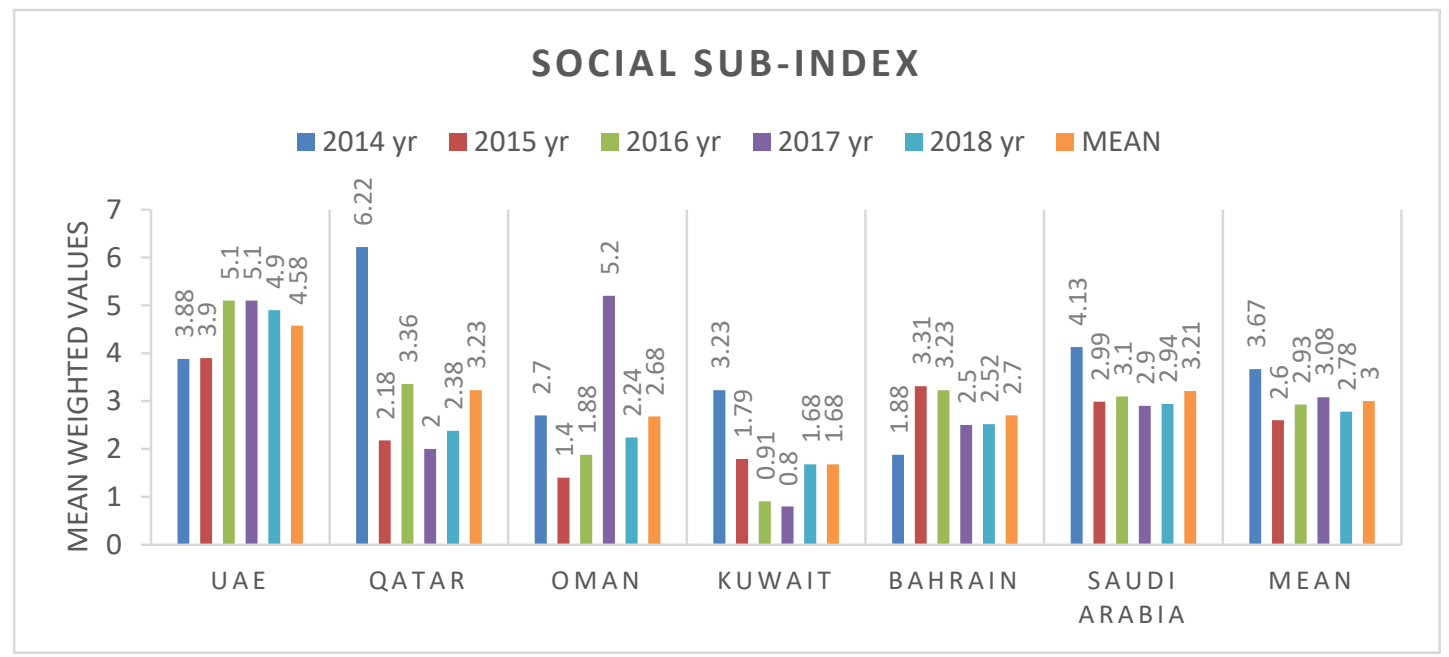

Figure 10. Social sub-index

(Compiled and created by the author based on original data from the GII reports 2014 - 2018)

The correlation between the politicsl / legal and the social sub-indexes (Figures $7 \& 10$ respectively) would also be expected to be high, and there is a strong " $\mathrm{r}$ " of 0.80 , or a correlation between the conducive business environment $(\mathrm{P} / \mathrm{L})$ 
and knowledge intensive employment, research and development and formal training programmes for future ventures.

The environmental sub-index indicates the degree to which the countries are concerned with the environmental impact of their production and consumption of oil and gas. Over the past decade, the domestic consumption of oil and gas has risen twice as fast in the Gulf states compared to the rest of the world average of $2.5 \%$. The spikes in figure 11 show Qatar (gas) and Kuwait as major culprits of cannibalisation of oil exports for domestic use. This is worrying in that there appears to little abatement to the predicted geometric growth projected to 2020 (Krane 2012). Investments in alternative energy supplies is slow due to the massive investments made in dependence on oil and gas, but the UAE has led the way with investments in solar and wind power.

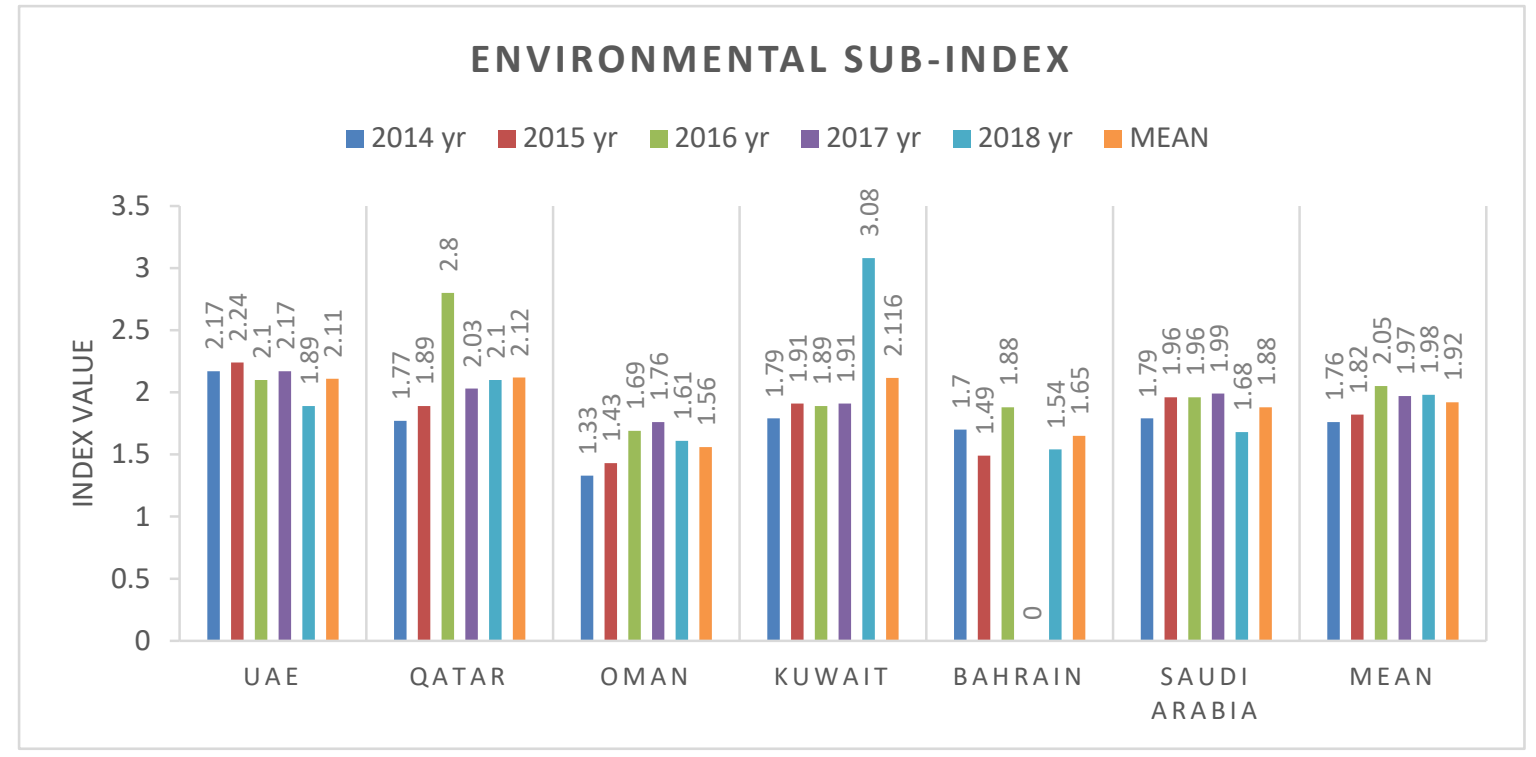

Figure 11. Environmental sub-index

(Compiled and created by the author based on original data from the GII reports 2014 -2018)

All of the GCC states have recognised the necessity to invest in alternative energy sources, to varying degrees of the sizes of investments. These cleaner energy investments will not pay dividends immediately, and there is a steep learning curve in the technology take up, for example the KSA has begun investments in nuclear power, which take time to embed into the overall energy supply and consumption infrastructures, as well as the scientific competence levels required to develop and build. Technology standards; government regulation; technology transfer from established global providers, in more mature markets, all need to be accommodated into the renewable's development framework (Al-Maamary, 2017).

\section{Interpretation}

The creation of the CCDI has been an attempt to measure the progress along the rentier state - technologically, knowledge based and innovation driven (TKI) continuum, by examining the extent to which each country has moved along the path towards increased diversification in TKI centred economic activities. When viewed this way, there are three stand-out countries making more headway, even if relatively marginal, than the other three, in all indexes of the previous sections, towards the TKI end of the continuum. They are the UAE, Qatar and KSA. The CCDI shows that the six GCC countries essentially split into two groups of three, that is the most advanced in the CCDI score by value being the UAE, Qatar, and KSA, with Oman, Kuwait, and Bahrain being laggards. The congruency between all of the sub-indexes country values (PESTEL) and CCDI is also a feature of the development and diversification patterns, especially the top three ranked countries, persistently having the highest sub-indexes values. The graphs in the data analysis chapter show that the UAE and KSA have clearly exhibited the highest degree of stability in their patterns of diversification, measured by the PETSEL indexes and ultimately the CCDI. The speed and rate of change has however been faster and greater in degree in the UAE, when averaged over the 2014/18 period under scrutiny.

Stability in the face of turbulent global economic conditions and the volatility of oil traded prices is a testimony to the degree of controlled development and diversification that has been exhibited particularly by the UAE and KSA. Some would argue that authoritarian, monarchic states exert hegemonic control maintaining that status quo. The political-legal sub-index shows that all of the countries have recognised the need for creating a business environment that promotes a regulatory framework that is conducive to entrepreneurialism and business development. Equally, and congruently, the 
social sub-index values show that plugging into the global business ecosystems, of and through research and development, and knowledge intensive employment is a considered and managed move with the UAE in particular, leading the way. The technological sub-index further indicates the direction of investment in producing and promoting techno-knowledge-innovation based industries and services, producing and promoting these attribute outputs (see appendix 1).

When the CCDI is disaggregated into the individual PESTEL sub indexes, the strategic intents, speed, scale, and stability exhibited by the GCC six, appears to highlight the measured, managed, economic model response to the diversification imperative. This echoes the point made by Al-Beraidi (2018) that the GCC states should pursue an Arabic model of neo-liberalism, in which the economic imperative, espoused and imposed by outsiders, reflecting their own axiological stances.

The sub-index measures show a willingness, in most of the states, to make economic structural adjustments, by making "significant investment in health, education and infrastructure, and implementing reforms to the business environment." (Miniaoui and Schiliro`2016, p 5). The authors go on to say that "[a] successful innovation strategy constitutes a coherent approach that seeks to coordinate disparate policies towards scientific research, technology commercialization, information and communication technology (ICT) investments, education, taxation, trade, intellectual property (IP), government procurement, and regulation in an integrated fashion that drives economic growth." (ibid p 5). With this in mind, and examining the attributes that make up the PETSEL sub-indexes, in appendix 1, the GCC states are showing slow, but deliberate positive progress in all of the policy areas indicated as necessities for a successful innovation strategy.

The year on year marginal reductions, in the majority of the countries' percentage of hydrocarbon revenues, reinforces the managed and measured approach of what could be termed the specific GCC centric liberalist model. The PESTEL sub-indexes data, aggregated into the CCDI, show an awareness on the part of the Gulf leaders, of the traps of historical western neo-liberalism, that could be categorised by debt crises, large scale privatisation programmes, rampant free market economics, political and social programmes causing population privation, and the commoditisation of technology, promoting technology for technologies sake (Al-Beraidi 2018). This research appears to indicate, for whatever moral and hegemonic motives, that there has been a piecemeal, studied, marginal diversification into the TKI economic sectors, whilst retaining an informed critical eye on volatile, and in the long run, diminishing returns, of hydrocarbon economic reservoirs.

\section{Conclusion}

The most prominent features revealed by the research are as follows. There is a high degree of congruence between the PESTEL factors in terms of individual country values in each sub-index, measured by Pearson's "r", and the CCDI. The six GCC countries appear to split into two groups in terms of their comparative development, according to the CCDI, with the UAE, Qatar and to a moderately lesser degree, the KSA more advanced in terms of diversification.

The diversification and development, towards the techno-knowledge-innovation mixed mode economy is incremental, but can definitely be seen to be part of the strategic intent of the countries' leaders. However incremental and marginal it is, there is a recognition that non-economic diversification carries greater risks than does diversification. In particular there are two PETSEL factors, the political and the economic sub-indexes, that show a correlation, with one (the political-legal) creating the business environment for the other (economic) to occur. The CCDI has also shown, in its trend data, the comparative patterns of technological and economic diffusion.

One picture that this research reveals, and brings into stark relief, is that the GCC country leaders appear to have the foresight to diversify and develop their economies, whilst being mindful of what has been termed in this dissertation, of the potential trap of neoliberalist arguments that potentially cause their citizens' privations (irrespective of the moral arguments regarding authoritarianism). This would appear to be a prudent strategy, where the necessary PESTEL structural reforms are in the nascent stages of introduction and diffusion. The creation of ecosystems, in wider regional and global contexts, indicates a willingness and propensity to diversify. The sovereign wealth funds may then be sued as the economic "pump primers" and as the vehicles to aid the diffusion through investments in technology and knowledge partnerships.

The development of ecosystems is an important potential area of future research, particularly business ecosystems facilitated by the SWFs. Unanticipated at the outset of this dissertation, the SWFs appear to be at the fulcrum of diversification and development to the mixed economic mode. Due to the opacity and confidentially of fund management, and costs of obtaining further data on the asset bases of the funds, this was not an area pursued to a larger degree in the current work. However, the SWFs have a great potential to support business ecosystem developments in future industries, as evidenced by the investments of the funds, particularly in the KSA and UAE, in strategic alliances in information systems, aerospace, technology and knowledge-based partnerships. This would have implication for the social contracts, economic diversification, technological and knowledge-based activities, education and strategic policy 
intent on the part of governments and private sectors.

The implicit prudence, embedded behind the headline figures of the CCDI, may herald the dawn of a new managed mode of GCC (Arabic) neo-liberalism. The state and private sectors working on social contracts that recognise, but manage change in tandem, based on Arabic cultural specificity. The precedent for this may be seen in the mature Scandinavian country models, where state and private sectors work with each other, within the country, and more widely within the EU regional meta PESTEL framework in differing degrees. The hydrocarbon abundance, of the GCC countries, would then, and is being used as an asset base to aid the structural transformations towards the mixed mode politico - economic - social - technological variables, measured by the CCDI. Within the broad church that is late rentierism, this research has helped to progress the debate relating to diversification, by the positioning of the GCC states on a continuum of diversification, specifically related to TKI industries.

\section{References}

Al-Beraidi, A. (2018). The Trap of Neoliberalism for GCC Countries: Salvaging an Economy or Drowning a Community? Contemporary Arab Affairs, 11(4), 63-82. https://doi.org/10.1525/caa.2018.114004

Al-Maamary, H. M., Kazem, H. A., \& Chaichan, M. T. (2017). Renewable energy and GCC States energy challenges in the 21st century: A review. International Journal of Computation and Applied Sciences IJOCAAS, 2(1), 11-18. https://doi.org/10.24842/1611/0018

Arab Development Portal. (2019).

http://www.arabdevelopmentportal.com/blog/success-and-shortcomings-gcc-economic-“vision"-documents, accessed September $10^{\text {th }}, 2019$.

Beblawi, H., \& Luciani, G. (eds.) (2015). The rentier state. Routledge. https://doi.org/10.4324/9781315684864

Cherif, R., Hasanov, F., \& Pande, A. (2017). Riding the energy transition: Oil beyond 2040. International Monetary Fund. https://doi.org/10.5089/9781484301128.001

Diemers, D., Lamaa, A., Salamat, J., \& Steffens, T. (2015). Developing a FinTech ecosystem in the GCC. Dubai: Strategy\&, 16.

Dutta, S., Lanvin, B., \& Wunsch-Vincent, S. (2014). The Global Innovation Index.

Dutta, S., Lanvin, B., \& Wunsch-Vincent, S. (2015). The Global Innovation Index 2015. Effective Innovation Policies for Development, Geneva: World Intellectual Property Organisation.

Dutta, S., Lanvin, B., \& Wunsch-Vincent, S. (2016). The Global Innovation Index 2016. Effective Innovation Policies for Development, Geneva: World Intellectual Property Organisation.

Dutta, S., Lanvin, B., \& Wunsch-Vincent, S. (2017). The Global Innovation Index 2017. Effective Innovation Policies for Development, Geneva: World Intellectual Property Organisation.

Dutta, S., Lanvin, B., \& Wunsch-Vincent, S. (2018). The Global Innovation Index 2018. Effective Innovation Policies for Development, Geneva: World Intellectual Property Organisation.

Ennis, C. (2018). Rentier-preneurship: Dependence and autonomy in women's entrepreneurship in the Gulf. POMEPS Studies, Jan, 29, 60-66.

Gray, M. (2011). A Theory of Late Rentierism 'in the Arab States of the Gulf. CIRS Occasional Papers. https://doi.org/10.2139/ssrn.2825905

Herb, M. (2018). Labor markets and economic diversification in the Gulf rentiers. POMEPS Studies, Jan, 29, 8-12.

Hertog, S. (2015). State and Private Sector in the GCC after the Arab Uprisings. Journal of Arabian Studies, 3(2), 174-195. https://doi.org/10.1080/21534764.2013.863678

Hertog, S. (2010). Defying the resource curse: explaining successful state-owned enterprises in rentier states. World Politics, 62(2), 261-301. https://doi.org/10.1017/S0043887110000055

Hvidt, M. (2013). Economic diversification in GCC countries: Past record and future trends.

Kinninmont, J. (2015). Future trends in the Gulf. Chatham House.

Akbarzadeh, S. (Ed.). (2019). Routledge handbook of international relations in the Middle East. Routledge.

Krane, J. (2015). Stability versus sustainability: energy policy in the Gulf monarchies. The Energy Journal, 1-21. https://doi.org/10.5547/01956574.36.4.jkra

Krane, J. (2018) Subsidy reform and tax increases in the rentier Middle East. POMEPS Studies, Jan., 29, 18-24. 
Levins, C. M. (2012). The rentier state and the survival of Arab absolute monarchies. Rutgers JL \& Religion, 14, 388.

Luciani, F. G. (2015b). Allocation vs. production states: A theoretical framework. In the rentier state, pp. 77-96. Routledge. https://doi.org/10.4324/9781315685229-4

Luciani, G. (2015a). The Arab State. Routledge. https://doi.org/10.4324/9781315685229

Mahmah, A. E., \& Kandil, M. E. (2019). The balance between fiscal consolidation and non-oil growth: The case of the UAE. Borsa Istanbul Review, 19(1), 77-93. https://doi.org/10.1016/j.bir.2018.05.002

Miniaoui, H., \& Schilirò, D. (2017). Innovation and entrepreneurship for the diversification and Growth of the Gulf Cooperation Council Economies. https://doi.org/10.11114/bms.v3i3.2594

Moore, C. H., Henry, C. M., \& Wilson, R. (eds). (2004). The politics of Islamic finance. Edinburgh University Press.

Moritz, J. (2018). Oil and societal quiescence: Rethinking causal mechanisms in rentier state theory. POMEPS Studies, Jan, 29, 40 - 43.

Moritz, J. A. (2016). Slick operators: revising Rentier State Theory for the modern Arab States of the Gulf.

Ozyavuz, A., \& Schmid, D. (2015). Persistence and Evolutions of the Rentier State Model in Gulf Countries.

Tok, M. E. (2018). Can GCC States Achieve Sustainable Economic Diversification and Development by Driving Entrepreneurship Efforts?

Ulrichsen, K. (2018). Endgames for Saudi Arabia and the United Arab Emirates in Yemen. POMEPS Studies, Jan, 29, 31-3.

Ulrichsen, K. C. (2018). Economic Inclusion in Gulf Cooperation Council (GCC) States: Findings from an Expert Survey.

World Bank Group. (2014). Doing Business 2015: Going Beyond Efficiency: Comparing Business Regulations for Domestic Firms in 189 Economies: a World Bank Group Flagship Report. World Bank Publications.

World Bank Group. (2015). Doing Business 2016: Going Beyond Efficiency: Comparing Business Regulations for Domestic Firms in 189 Economies: a World Bank Group Flagship Report. World Bank Publications.

World Bank Group. (2016). Doing Business 2017: Going Beyond Efficiency: Comparing Business Regulations for Domestic Firms in 189 Economies: a World Bank Group Flagship Report. World Bank Publications.

World Bank Group. (2017). Doing Business 2018: Going Beyond Efficiency: Comparing Business Regulations for Domestic Firms in 189 Economies: a World Bank Group Flagship Report. World Bank Publications.

World Bank Group. (2018). Doing Business 2019: Going Beyond Efficiency: Comparing Business Regulations for Domestic Firms in 189 Economies: a World Bank Group Flagship Report. World Bank Publications.

Yamada, M. (2018). Exploring why institutional upgrading is not so easy in rentier states. POMEPS Studies, 2018 Jan, 29, 13-17.

Young, K. (2018). What's yours is mine: Gulf SWFs as a barometer of state-society relations. POMEPS Studies. Jan, 29, 44-50.

Young, K. E. (2018). The Difficult Promise of Economic Reform in the Gulf. 
Appendix 1. List of attributes used in the creation of the CCDI, (Author's Own)

\section{PESTEL FACTORS \& CCDI ATTRIBUTES LIST}

\section{POLITICAL / LEGAL (28\% of CCDI)}

Political environment

Political stability \& safety

Government effectiveness

Regulatory environment

Regulatory quality

Rule of law

Business environment

Education

Expenditure on education, \% GDP

School life expectancy, years

PISA scales in reading, maths \& science/100

Pupil-teacher ratio, secondary

Research \& development (R\&D)

Researchers, FTE/10000 pop

Gross expenditure on R\&D, \% GDP

Global R\&D companies, top 3, mn US\$

\section{TECHNOLOGICAL (38\% of CCDI)}

ICT access

ICT use

Government's online service.

Electricity output, $\mathrm{kWh} / \mathrm{cap} \$ 1000$

Logistics performance

Knowledge absorption

Intellectual property payments, \% total trade

High-tech net imports, \% total trade.

ICT services imports, \% total trade

FDI net inflows, \% GDP

Research talent \% in business enterprise

Knowledge creation

Knowledge impact

Growth rate of PPP\$GDP/worker, \%

Knowledge diffusion

Intellectual property receipts, \% total trade.

High-tech net exports, \% total trade.

ICT services exports, \% total trade

FDI net outflows, \% GDP

ICTs \& business model creation

ICTs \& organizational model creation

\section{ECONOMIC (13\% of CCDI)}

Credit

Investment

Market capitalization, \% GDP

Venture capital deals/bn PPP\$ GDP

Trade, competition, \& market scale

Intensity of local competition

Domestic market scale, bn PPP\$ / 10

\section{SOCIAL (14\% of CCDI)}

Knowledge workers

Knowledge-intensive employment, \%

Firms offering formal training, \% firms

GERD performed by business, \% GDP

GERD financed by business, $\%$

Females employed w/advanced degrees, $\%$

Innovation linkages.

Patent families 2+ offices/bn PPP\$ GDP

ENVIRONMENTAL (7\% of CCDI)

Ecological sustainability

GDP/unit of energy use

Environmental performance

ISO 14001 environmental certificates/bn PPP\$ GDP expenditure

This table shows the Innovation Inputs and Innovation Outputs. The colour coding legend shows:

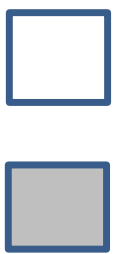

Innovation Inputs $(x 39=69 \%)$

Innovation Outputs $(\mathbf{x 1 7}=\mathbf{3 1 \%})$

The input / output proportions are the same as in the original GII databases.

This list of 56 attributes in this table are a concentrated version of the 103 attributes in the GII reports (2014 - 2018), with an emphasis on the knowledge economy aspects. 
Appendix 1a. An explanation of the PETSEL attributes chosen in appendix 1

\begin{tabular}{|l|l|}
\hline POLITICAL/LEGAL & $\begin{array}{l}\text { This relates to the business environment and the influence of the government in } \\
\text { creating a viable infrastructure in terms of legal frameworks, education, and } \\
\text { support for R\&D. The attributes were chosen as direct or proxy measures for the } \\
\text { "ease of doing business", facilitating an environment which fosters trust, for } \\
\text { business start-ups, and an ongoing private sector, in R\&D and education. }\end{array}$ \\
\hline ECONOMIC & $\begin{array}{l}\text { These attributes focus on the size and scale of markets and competition fostered } \\
\text { in the domestic economies. }\end{array}$ \\
\hline SOCIAL & $\begin{array}{l}\text { Knowledge, skills of the domestic workforce, through training and skills } \\
\text { development. In addition, the global expenditure on R\&D has been included the } \\
\text { attributes, to factor in the trend for each GCC state with respect to the global } \\
\text { outlook. }\end{array}$ \\
\hline TECHNOLOGICAL & $\begin{array}{l}\text { The main attributes of concern in the factor are ICT; innovations, business model } \\
\text { creation; intellectual property expenditure; which all relate to the extant research } \\
\text { outlined in the literature reviewed in this paper, as the way forward for the GCC } \\
\text { states in terms of diversification and development towards the mixed mode } \\
\text { economy. }\end{array}$ \\
\hline ENVIRONMENTAL & $\begin{array}{l}\text { The ecological/environmental footprint and expenditure on alternative } \\
\text { technologies are behind the headline figures used in our calculations in these } \\
\text { attributes. }\end{array}$ \\
\hline
\end{tabular}

Appendix 2. Sovereign Wealth Funds of Gulf States, (Compiled by the Author from Sovereign Wealth Fund Institute, July 2019)

\begin{tabular}{|c|c|c|}
\hline $\begin{array}{l}\text { RANKING BY } \\
\text { TOTAL ASSETS } \\
\end{array}$ & $\begin{array}{l}\text { SOVEREIGN WEALTH FUNDS } \\
\text { IN THE TOP } 75 \text { WORLD RANKINGS }\end{array}$ & $\begin{array}{l}\text { ASSETS UNDER MANAGEMENT } \\
\text { (AUM) }\end{array}$ \\
\hline $\begin{array}{l}3 \\
12 \\
13 \\
25 \\
66\end{array}$ & $\begin{array}{l}\text { UAE } \\
\text { Abu Dhabi Investment Authority (ADIA) } \\
\text { Investment Corporation of Dubai (ICD) } \\
\text { Mubadala Investment Company PJSC (Mubadala) } \\
\text { Emirates Investment Authority (EIA) } \\
\text { Sharjah Asset Management Holding LLC United } \\
\text { Arab Emirates } \\
\text { TOTAL }\end{array}$ & $\begin{array}{l}\$ 696,660,000 \times 10^{3} \\
\$ 239,379,000 \times 10^{3} \\
\$ 228,934,000 \times 10^{3} \\
\$ 45,000,000 \times 10^{3} \\
\$ 793,202 \times 10^{3} \\
22,893,400,000,981,832,202 \times 10^{3}\end{array}$ \\
\hline 4 & $\begin{array}{l}\text { KUWAIT } \\
\text { Kuwait Investment Authority (KIA) }\end{array}$ & $\$ 592,000,000 \times 10^{3}$ \\
\hline 10 & $\begin{array}{l}\text { KSA } \\
\text { Public Investment Fund of Saudi Arabia (PIF) }\end{array}$ & $\$ 320,000,000 \times 10^{3}$ \\
\hline 11 & $\begin{array}{l}\text { QATAR } \\
\text { Qatar Investment Authority (QIA) }\end{array}$ & $\$ 320,000,000 \times 10^{3}$ \\
\hline 33 & $\begin{array}{l}\text { OMAN } \\
\text { State General Reserve Fund of the Ministry of } \\
\text { Finance of the Sultanate of Oman (Oman SGRF) } \\
\text { Oman Investment Fund Holding Company LLC } \\
\text { (OIF) } \\
\text { TOTAL }\end{array}$ & $\begin{array}{l}\$ 22,140,900 \times 10^{3} \\
\$ 3,415,500 \times 10^{3} \\
\$ 25,556,400 \times 10^{3}\end{array}$ \\
\hline 36 & $\begin{array}{l}\text { BAHRAIN } \\
\text { Mumtalakat: Sovereign Wealth Fund in Bahrain }\end{array}$ & $\$ 16,670,200 \times 10^{3}$ \\
\hline
\end{tabular}


Appendix 2a. Sovereign Wealth Funds of Gulf States, Investment Sectors and total deals. (Compiled by the Author from Sovereign Wealth Fund Institute, July 2019)

\begin{tabular}{|l|l|l|}
\hline SWF INVESTMENT SECTOR & TOTAL DEALS NO. & TOTAL DEALS \% \\
\hline Technology & 49 & 14.4 \\
\hline Fintech & 41 & 12.1 \\
\hline Biotechnology & 29 & 8.5 \\
\hline & & \\
\hline
\end{tabular}

\section{Copyrights}

Copyright for this article is retained by the author(s), with first publication rights granted to the journal.

This is an open-access article distributed under the terms and conditions of the Creative Commons Attribution license which permits unrestricted use, distribution, and reproduction in any medium, provided the original work is properly cited. 